\title{
ANÁLISE MICROBIOLÓGICA DA ÁGUA DE CISTERNAS DESTINADAS PARA CONSUMO HUMANO
}

Kelly Cardoso da Silva ${ }^{1}$, Paulo Ricardo de Sá da Costa Leite ${ }^{2}$, Jorge Freitas Cieslak $^{3}$, Emiliane dos Santos Belo ${ }^{3}$, Valéria Bonifácia Marra da Silva ${ }^{4}$

${ }^{1}$ Licenciada em Ciências Biológicas, Instituto Federal Goiano - Campus Ceres (kellynha.cs@hotmail.com; paulo.ricardo@ifgoiano.edu.br) Ceres (GO) - Brasil

${ }^{2}$ Docente, Instituto Federal Goiano - Campus Ceres

${ }^{3}$ Técnico em laboratório, Instituto Federal Goiano - Campus Ceres

${ }^{4}$ Graduanda em Zootecnia, Instituto Federal Goiano - Campus Ceres

Recebido em: 08/09/2015 - Aprovado em: 14/11/2015 - Publicado em: 01/12/2015 DOI: http://dx.doi.org/10.18677/Enciclopedia_Biosfera_2015_001

\begin{abstract}
RESUMO
O conhecimento dos fatores que contribuem para a contaminação da água é muitas vezes desconhecido pela população, o que faz com que muitas pessoas consumam este liquido fora dos padrões de potabilidade. Independente das condições socioeconômicas, a água é um bem ambiental indispensável às necessidades humanas e é direito de todos. O presente estudo objetivou verificar a qualidade microbiológica das águas de cisternas destinada para consumo humano no município de Uruana - GO, bem como determinar o número mais provável de coliformes totais e de coliformes termotolerantes. Foram analisadas amostras de água de vinte cisternas, coletadas em cinco bairros, na qual foi aplicada a técnica convencional dos tubos múltiplos, expressando os resultados em Número Mais Provável - NMP. Os dados foram submetidos à análise estatística descritiva e foi realizada correlação simples entre a distância da cisterna às fossas e o número de coliformes no programa estatístico Assistat. Os resultados obtidos a partir da análise das amostras indicaram contaminação de coliformes totais e termotolerantes revelando que o consumo de água de cisterna situada próximas a fossas no município de Uruana oferece risco à saúde pública, por apresentar percentual relevante de contaminação microbiológica e está em desacordo com a legislação vigente que estabelece os índices de potabilidade desejáveis.
\end{abstract}

PALAVRAS-CHAVE: Coliformes totais. Coliformes termotoletantes. Contaminação.

\section{MICROBIOLOGICAL ANALYSIS OF CISTERNS WATER FOR HUMAN CONSUMPTION}

\footnotetext{
ABSTRACT

The knowledge of factors that contribute to water contamination is often unknown by the population, what causes many people to consume this liquid out of potability standards. Irrespective of socioeconomic conditions, water is an environmental good indispensable to human needs and is right for everyone. The present study aimed to ENCICLOPÉDIA BIOSFERA, Centro Científico Conhecer - Goiânia, v.11 n.22; p.2810 2015
} 
determine the microbiological quality of water cisterns intended for human consumption in the municipality of Uruana-Go, as well as determine the most probable number of total coliforms and fecal coliforms. Wereanalyzed water samples of twenty cisterns, collected in five neighborhoods, in which was applied to conventional technique of multiple tubes, expressing the results in Most Probable Number - MPN. Data were subjected to descriptive statistical analysis and was performed simple correlation between the away the cistern and the cesspit and the number of coliforms in Assistat statistical program. The results obtained from the analysis of the samples indicated contamination of total and fecal coliforms andrevealed that consumption of cistern water located next the cesspit in the city of Uruana offers public health risk, because for presents significant percentage of microbiological contamination and is at odds with current legislation establishing the indices potability desirable.

KEYWORDS: Total coliforms. Thermotolerant coliforms. Contamination.

\section{INTRODUÇÃO}

A utilização da água pela sociedade humana visa atender suas necessidades pessoais, atividades agrícolas, industriais e sociais. No entanto, essa diversificação no uso da água, quando realizada de forma inadequada, provoca alterações na sua qualidade, comprometendo os recursos hídricos e, por consequência, seus usos para os diversos fins. A qualidade da água é aspecto indispensável, quando se trata dos seus principais usos, em especial, para fins como o abastecimento humano (SOUZA et al., 2014).

O abastecimento de água em quantidade e qualidade necessária constitui grande preocupação para a humanidade, principalmente, pela escassez desse recurso e pela deterioração das águas dos mananciais (SANTOS \& LABADESSA, 2012; SANTOS et al., 2013). Nesse sentido, é de suma importância a criação de mais programas para conscientizar a população, principalmente os moradores da zona rural, sobre práticas sanitárias do tratamento de água, higiene e educação ambiental (PEREIRA et al., 2011; SILVA et al., 2012). Com o conhecimento da populações e a criação de novos programas de uso adequado da água, as comunidades desvaforáveis melhorariam a qualidade da água, assim evitando doenças (BARROS et al., 2013).

Em muitos países em desenvolvimento, é observado que a qualidade da água ainda é um limitante para a saúde pública, principalmente relacionada a diversas doenças e mortes (AUGUSTO et al., 2012). Nas periferias das cidades, onde se encontram o maior número de habitantes de baixa renda, que sofrem com rede de tratamento de água e esgoto ineficazes e muitas vezes inexistentes, a população local geralmente utiliza água de cisternas escavadas próximas a locais poluídos e contaminados. As cisternas são uma forma de armazenamento de água e geralmente utilizadas por pessoas com baixos índices socioeconômicos que muitas vezes não realizam o controle da qualidade da água, sendo, desse modo, passível de contaminação por coliformes totais e termotolerantes (MENEZES et al., 2013; SILVA NETO et al. 2013; MENEZES et al., 2015).

Além disso, o desconhecimento da distância adequada entre poçoslcisternas e recursos hídricos pode aumentar a probabilidade de contaminação da água. CAPELETTO (2000) recomenda pelo menos quinze metros de distância para assegurar a qualidade da água, tornando-a livre de contaminação por bactérias patogênicas.

Em escala mundial, provavelmente as bactérias patogênicas mais importantes 
transmitidas pela água são Salmonella typhi, causadora da febre tifóide, e Vibrio cholerae, causador da cólera. Embora S. typhi possa ser transmitida por alimentos contaminados e pelo contato direto com indivíduos infectados, a forma de transmissão mais comum e grave pode ocorrer pela água o que ocasiona as doenças diarréicas (MADIGAN et al., 2010; OLIVEIRA et al. 2012).

SILVA et al. (2012) avaliaram a qualidade da água de cisterna de uma região do semi-árido do estado de Minas Gerais e verificarm que das trinta e cinco amostras analisadas para pesquisa de Escherichia coli, importante indicador de contaminação fecal, apenas oito mostras (23\%) estavam em conformidade com o critério de potabilidade.

SILVA (2013) avaliou a água de cisterna no interior do estado da Bahia e observou que a contaminação por coliformes termotolerante pode ter sido causada por fatores como falta de limpeza da cisterna, da superfície de coleta e pela presença de árvores próximas às cisternas. MESQUITA et al. (2014) analisaram água destinada ao consumo humano em um município do Pará e verificaram que $54,17 \%$ das amostras de água coletada estavam fora dos padrões de potabilidade para coliformes totais e 4,17\% para Escherichia coli.

Levando em consideração o papel fundamental da qualidade da água na vida dos seres humanos, entende-se, portanto que há a necessidade de uma avaliação da qualidade da água de cisternas, principalmente em localidades que não apresentam rede de esgoto e água tratada, e por se localizarem próximas às fossas, havendo a possibilidade de contaminação do lençol freático e consequentemente da população local.

Diante de tais considerações, objetivou-se verificar a qualidade microbiológica das águas de cisternas destinadas para consumo humano, localizadas no município de Uruana-GO.

\section{MATERIAL E MÉTODOS}

O estudo foi realizado no período de fevereiro a maio de 2014 no município de Uruana - GO, nos bairros desprovidos de rede de esgoto e considerados periféricos. Foram selecionadas residências que possuíam cisterna, sendo coletadas amostras de água de vinte cisternas em cinco bairros, quatro amostras por bairro, as quais foram submetidas à análise microbiológica para a pesquisa de microorganismos do grupo coliformes.

Para a coleta das amostras, foi realizada, com o auxílio de gaze, a limpeza das torneiras com álcool $70 \%$ que ficaram abertas por um período de quatro a cinco minutos, sendo posteriormente coletados em frascos estéreis, aproximadamente, $150 \mathrm{~mL}$ de água. As amostras foram acondicionadas em caixa isotérmica e transportadas para o Laboratório de Microbiologia do Instituto Federal GoianoCâmpus Ceres.

Para a pesquisa de micro-organismos do grupo coliformes foi realizada a técnica convencional dos tubos múltiplos, com testes presuntivos e confirmativos, seguindo a metodologia de SILVA et al. (1997). Antes da análise das águas os frascos foram invertidos 25 vezes, em arco de $30 \mathrm{~cm}$, para facilitar a homogeneização da amostra. Para o teste presuntivo foi utilizado o Caldo Lactosado em concentração dupla sendo distribuídos $10 \mathrm{~mL}$ da amostra em cada tubo, no total de cinco tubos, em seguida inoculou-se $1 \mathrm{~mL}$ da amostra em outros cinco tubos, finalizando a terceira sequência inoculando $0,1 \mathrm{~mL}$ da amostra em mais cinco tubos . As amostras foram levadas para a estufa por 24/48 horas, a uma temperatura de $35^{\circ} \mathrm{C}$. As amostras com o resultado positivo (formaçã o de gás no tubo de Durhan) no 
teste presuntivo passaram para o teste confirmativo.

Para a confirmação de micro-organismos do grupo de coliformes totais, alíquotas dos tubos positivos no Caldo lactosado foram transferidas com auxílio de uma alça de platina devidamente flambada para tubos contendo Caldo Verde Brilhante. Os tubos foram incubados a 35o $\mathrm{C}$ por 24-48 horas. Para o teste de coliformes termotolerantes, uma alíquota das amostras positivas no caldo verde brilhante foi transferida com para tubos contendo $10 \mathrm{~mL}$ do meio de cultura Caldo Escherichia coli (EC). As amostras foram colocadas em estufa bacteriológica a $44{ }^{\circ} \mathrm{C}$ durante 24/48 horas. Após esse período as amostras foram analisadas sendo que os tubos com formação de gás no tubo de Durhan confirmaram a presença de coliformes termotolerantes.

Os dados foram interpretados de acordo com o com o Manual Prático de análises de Água da Fundação Nacional de Saúde (BRASIL, 2009) e submetidos à análise estatística descritiva (média, desvio padrão, valor mínimo e máximo) e foi realizada correlação simples entre a distância da cisterna às fossas e o número de coliformes no programa estatístico Assistat (2009).

\section{RESULTADOS E DISCUSSÃO}

De acordo com os resultados obtidos foi possível constatar que todas as amostras analisadas estavam fora dos padrões de potabilidade. Nota-se que, de acordo com o gráfico 1, oito amostras (40\%) apresentaram alto valor do Número Mais Provável (NMP), sendo maior que 1600. Três amostras (15\%) com valor igual a 1600 NMP, outras três valores entre 100 a 900 NMP e seis (30\%) apresentaram valores entre 30 e 100 NMP. Na análise da estatística descritiva, Tabela 1, observase que a média de micro-organismos do grupo coliformes totais foi elevada com 953 NMP, enquanto que a de coliforme termotolerante de 651 NMP.

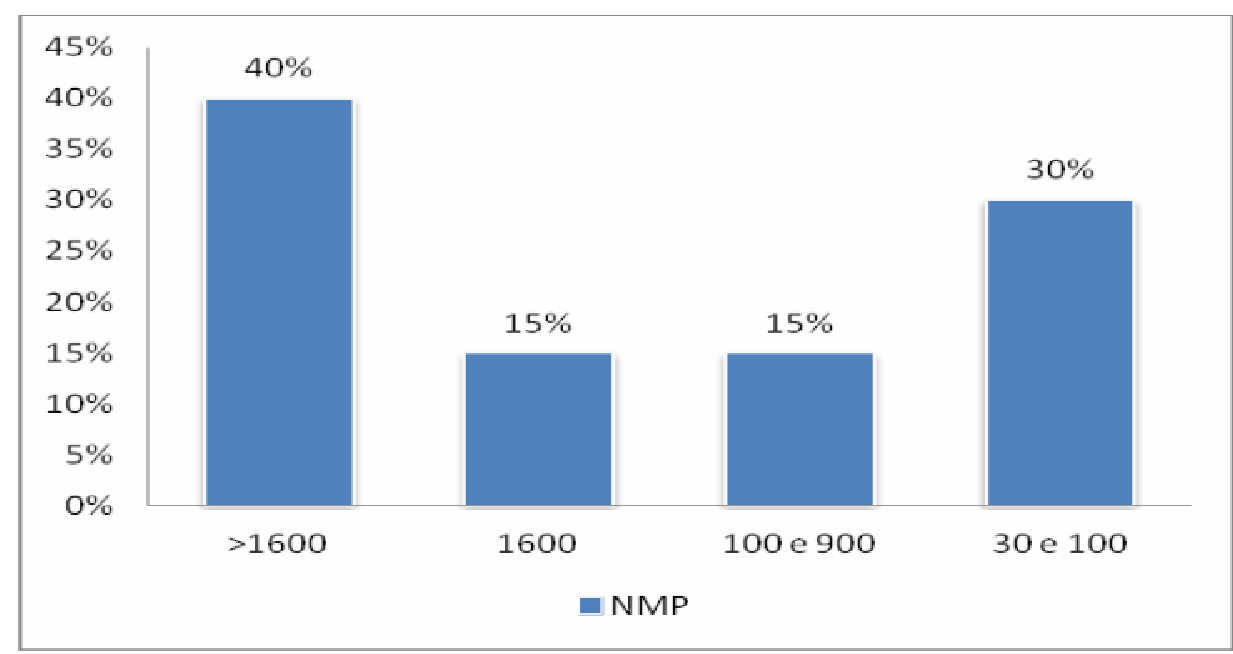

FIGURA 1. Porcentual de amostras analisadas de acordo com 0 NMP de coliformes totais.

TABELA 1. Estatística descritiva para as amostras analisadas.

\begin{tabular}{lcccc}
\hline Coliformes Totais & Média & Desvio & Valor & Valor \\
& & padrão & mínimo & máximo \\
Coliformes & 953,6 & 756,800 & 30 & $>1600$ \\
Termotolerantes & 651,1 & 739,874 & 6 & $>1600$ \\
\hline
\end{tabular}


Os resultados obtidos nesse estudo são semelhantes ao trabalho desenvolvido por REIS et al. (2010) na Cidade de Campo Limpo de Goiás, que verificaram contaminação da água de cisterna por micro-organismos do grupo de coliformes totais. É sabido que os coliformes totais apontam a possibilidade de poluição fecal, traduzindo como risco potencial de contaminação da água por microorganismos patogênicos, incluindo bactérias, vírus e protozoários. A presença de coliformes termotolerantes em águas não tratadas indica que a água pode está poluída com fezes de humanos ou animais, com o risco de serem encontrados micro-organismos patogênicos, podendo ocasionar danos a saúde quando ingeridas (BASTOS et al., 2000; OLIVEIRA et al., 2012).

BEZERRA et al. (2010) realizaram um trabalho na localidade rural Cipós dos Tomaz, município de Crato, situado na região do Cariri, ao Sul do Ceará, com o objetivo de realizar análise microbiológica das águas de 10 cisternas construídas pelo Projeto 1 Milhão de Cisternas e observaram que quatro amostras apresentaram contaminação por coliformes totais e três apresentaram resultados insatisfatórios para Escherichia coli.Do mesmo modo, AMORIM \& PORTO (2001) realizaram estudo para avaliar a qualidade bacteriológica da água de 14 cisternas da comunidade de Volta do Riacho localizada no município de Petrolina-PE e verificaram que os valores de NMP/100 mL variaram de 40 a superior a 1600 $\mathrm{NMP} / 100 \mathrm{~mL}$ de coliformes. Os autores relataram ainda que a ausência de medidas de prevenção de contaminação, principalmente o uso da desinfecção da água pelo cloro, proporcionou contagem elevada de coliformes.

Com relação aos resultados de coliformes termotolerantes, pode observar que todas as amostras analisadas apresentaram resultado positivo, com diferentes valores de NMP (Tabela 2).

TABELA 2. Resultados das amostras dos testes confirmativos para Número Mais Provável (NMP) de coliformes termotolerantes, utilizando séries de cinco tubos, conforme Manual de análise de água da Brasil (2009).

$\begin{array}{cc}\text { Amostra } & \text { NMP } \\ 1 & >1600 \\ 2 & >1600 \\ 3 & 1600 \\ 4 & 34 \\ 5 & >1600 \\ 6 & 6 \\ 7 & >1600 \\ 8 & 70 \\ 9 & 130 \\ 10 & 220 \\ 11 & 34 \\ 12 & 900 \\ 13 & 1600 \\ 14 & >1600 \\ 15 & 230 \\ 16 & 40 \\ 17 & 50 \\ 18 & 23 \\ 19 & 50 \\ 20 & 30 \\ & \end{array}$

Os resultados do presente estudo estão de acordo com FREITAS et al. (2001) 
que verificaram contaminação, por coliformes termotolerantes, da água de cisterna e da rede de abastecimento em sessenta por cento das amostras analisadas em duas micro-regiões de municípios do estado do Rio de Janeiro. Da mesma forma, BRITO et al. (2005) avaliaram 60 cisternas na Comunidade de Atalho, município de Petrolina-PE e encontraram presença de coliformes termotolerantes em $73 \%$ das amostras.

No Brasil, a portaria vigente para qualidade da água é a Portaria no 2914 do Ministério da Saúde, porém ela define padrões de potabilidade para água tratada. A Portaria define água potável como água que atenda ao padrão de potabilidade estabelecido nesta Portaria e que não ofereça riscos à saúde (MINISTÉRIO DA SAÚDE, 2011). De outro modo, a Portaria no 518 do Ministério da Saúde define água potável como aquela destinada para consumo humano cujos parâmetros microbiológicos, físicos, químicos e radioativos atendam ao padrão de potabilidade e que não ofereça riscos à saúde. Essa mesma portaria ressalta que em amostras individuais procedentes de poços, fontes, nascentes e outras formas de abastecimento sem distribuição canalizada, toleram-se a presença de coliformes totais, na ausência de Escherichia coli e, ou, coliformes termotolerantes (MINISTÉRIO DA SAÚDE, 2004). A água para consumo humano deve, portanto apresentar ausência de E. coli ou coliformes termotolerantes.

O presente estudo apresentou resultados preocupantes, pois de acordo com os moradores das residências visitadas na cidade de Uruana-GO, a água da cisterna é para consumo humano, sendo que consumiam a água sem nenhum processo de desinfecção, como a utilização do cloro, por exemplo. Ainda, de acordo com os moradores, a água era retirada da cisterna direto para filtros ou, em alguns casos, para garrafas de água. Assim, é importante ressaltar que mesmo límpida a água pode apresentar micro-organismos contaminantes, causadores de doenças de veiculação hídrica, tornando-a imprópria para consumo.

Com relação aos resultados de distância entre cisternas e fossas foi observado que a maioria das cisternas estavam próximas às fossas, sendo oito (40\%) das cisternas localizadas de 5 a 10 metros, dez (50\%) de 10 a 15 metros e duas (10\%) de 15 a 20 metros (Figura 2).

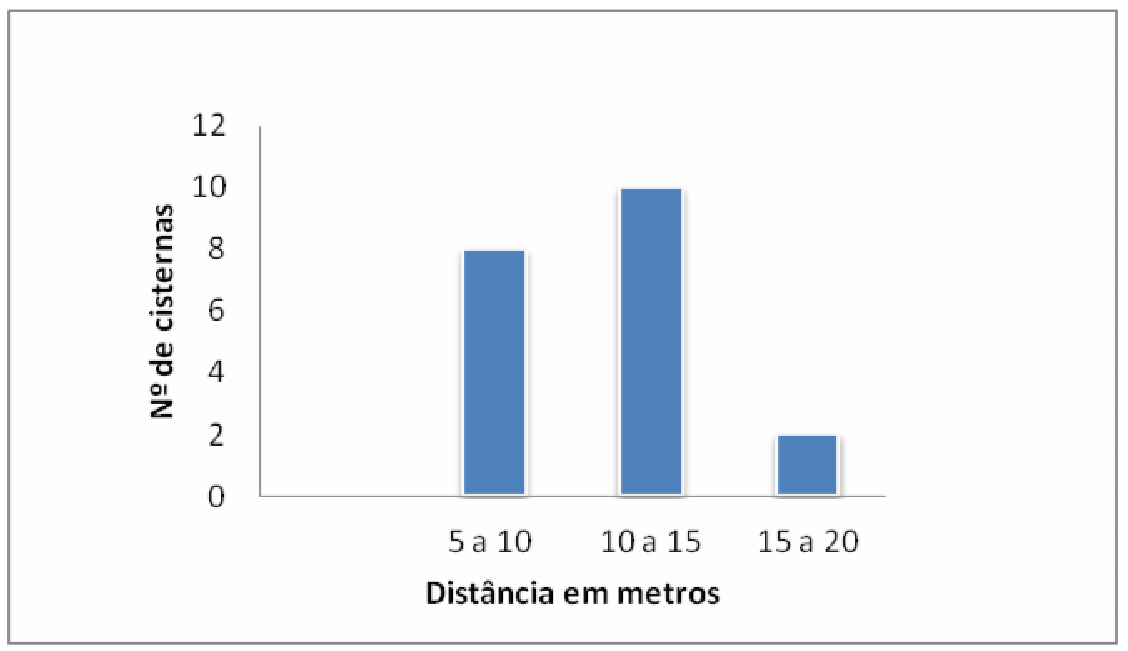

FIGURA 2. Distância entre cisternas e fossas.

Foi observada correlação negativa (Tabela 3) entre a distância da cisterna para a fossa com relação aos micro-organismos do grupo coliforme, sendo que na 
medida em que diminuía a distância da cisterna para a fossa aumentada o Número Mais Provável de coliformes.

TABELA 3. Correlação entre a distância das fossas às cisternas para os resultados de coliformes totais e termotolerantes.

\begin{tabular}{ccc}
\hline Correlação & Coeficiente de Correlação $(r)$ & Significativo \\
C. Totais x C. Termotolerantes & 0.7142 & $*$ \\
C. Totais x Distância & -0.5436 & $*$ \\
C. Termotolerantes x Distância & -0.6002 & $*$ \\
\hline
\end{tabular}

${ }^{* *}$ significativo a $1 \%{ }^{*}$ significativo a $5 \%$

Um fator que pode ter contribuído para contaminação da água com coliformes é a proximidade entre cisternas e fossas, de maneira que as fezes humanas contaminam o lençol freático que abastece as cisternas. Vale ressaltar que as bactérias do grupo coliforme, por serem habitantes normais do intestino humano, estão presentes em águas poluídas por matéria fecal. Assim, a existência de fossas ao invés de um sistema eficaz de esgoto é um problema na cidade de Uruana, pois a contaminação do lençol freático por fezes humanas pode deixar a população susceptível à micro-organismos patogênicos.

Segundo a Fundação Nacional de Saúde - BRASIL - (2006) deve ser respeitado, por medidas de segurança, a distância mínima de 15 metros entre a cisterna e a fossa, e de 45 metros, para os demais focos de contaminação, como, chiqueiros, estábulos, valões de esgoto, galerias de infiltração e outros, que possam comprometer o lençol d'água que alimenta o poço.

Todas as residências visitadas na cidade de Uruana possuíam fossas devido à não terem acesso a rede de esgoto, o que pode ter contribuído para a contaminação da água. Além disso, destacam-se também falhas no setor público de fiscalização que não atua de forma eficiente na preservação, manutenção e principalmente conscientização da população, quanto aos cuidados fundamentais com higiene. De acordo com SANTANA et al. (2015), as caixas d'água e bebedouros, devem ser higienizados para evitar contaminações. Portanto o monitoriamento e manutenção devem ser periódicos.

No presente estudo, durante a coleta das amostras, foi observado que as águas a serem analisadas possuíam aspecto límpido, porém alguns proprietários relataram que a limpeza das caixas de água não é um hábito comum, sendo que afirmaram passar até mais de um ano sem realizar a limpeza das caixas. Para que a água armazenada nas caixas tenha sua potabilidade preservada, é importante que os reservatórios permaneçam devidamente vedados e protegidos, bem como limpos e desinfetados, no mínimo, semestralmente (CVS, 2011). A descontaminação desta água poderia ser efetuada através do uso do hipoclorito de sódio, e da mesma forma, fervendo e filtrando a água, antes de consumi-la. Porém, os proprietários das residências abastecidas com água de cisternas na cidade de Uruana relataram que não é hábito comum tais processos de descontaminação da água. 


\section{CONCLUSÕES}

As águas coletadas de cisternas localizadas na cidade de Uruana-GO estão em desacordo com a legislação vigente por apresentarem número elevado de microorganismos do grupo coliformes. A contaminação da água pode ter sido, possivelmente, ocasionada pela distância inadequada entre as fossas e cisternas 0 que pode levar à problemas de saúde pública aos moradores das residências visitadas.

\section{REFERÊNCIAS}

AMORIM, M C.; PORTO, E R. Avaliação da qualidade bacteriológica das águas de cisternas: estudo de caso no município de Petrolina-PE. In: 3 Simpósio Brasileiro de Captação de Água de Chuva No Semi-Árido, 2001. Pernambuco - PE. Pernambuco: ABCMAC, 2001.

AUGuSto, L. G. S.; GURNEL, I. G. D.; CÂMARA NETO, H. F.; MELO, C. H.; COSTA, A. M. O contexto global e nacional frente aos desafios do acesso adequado à água para consumo humano. Revista Ciência e Saúde Coletiva, Rio de Janeiro, v. 17, n. 6, 1511-1522, Jun. 2012.

BARROS, J. D. S.; TORQUATO, S. C.; AZEVEDO, D. C. F.; BATISTA, F. G. Percepção dos agricultores de Cajazeiras na Paraíba, quanto ao uso de água de chuva para fins potáveis. Revista Holos, Rio Grande do Norte, v. 2, p. 50-65, 2013.

BASTOS, R. K. X.; BEVILACQUA, P. D.; NASCIMENTO, L. E.; CARVALHO, G. R. M.; SILVA, C. V. Coliformes como indicadores da qualidade da água: alcance e limitações. In: Congresso Internacional de Engenharia Sanitária e Ambiental. Porto Alegre. Anais... Rio de Janeiro: Associação Brasileira de Engenharia Sanitária e Ambiental, 2000.

BEZERRA, N. S.; SOUSA, M. J. G.; PINHO, A. I. Análise Microbiológica de Água de Cisternas na Localidade Cipó dos Tomaz, Município do Crato-Ce. Cadernos de Cultura e Ciência. Ano IV, v.1, n. 2, 2010.

BRASIL. Fundação Nacional de Saúde. Manual de Saneamento. 3aㅡ ed. Brasília: Fundação Nacional de Saúde - FUNASA, 2006. 408p.

BRASIL. Fundação Nacional de Saúde. Manual prático de análise de água. 3aㅡ ed. rev. - Brasília: Fundação Nacional de Saúde - FUNASA, 2009.

BRITO, L. T. L.; PORTO, E. R.; SILVA, A. S.; SILVA, M. S. L.; HERMES, L. C.; MARTINS, S. S. Avaliação das características físico-química e bacteriológicas das águas de cisternas da comunidade de Atalho, Petrolina- PE. In: Simpósio Brasileiro de Captação e Manejo de Água de Chuva, Teresina, PI, 2005.

CAPELETTO, A. Biologia e Educação Ambiental. São Paulo: Ática. 2000, 224 p.

COMUNICADO CENTRO DE VIGILÂNCIA SANITÁRIA - CVS 006, de 12 de Janeiro de 2011. Limpeza e Desinfecção de Caixas-d'água. Diário Oficial do Estado de São Paulo, São Paulo, 2011. 
FREITAS, B. M.; BRILHANTE, O. M.; ALMEIDA, L. M. Importância da análise de água para a saúde pública em duas regiões do Estado do Rio de Janeiro: enfoque para coliformes fecais, nitrato e alumínio. Caderno de Saúde Pública, Rio de Janeiro, v.17 n.3 p.651-660, mai-jun, 2001.

MADIGAN, M. T.; MARTINKO, J. M.; DUNLAP, P. V.; CLARK, D. P. Microbiologia de Brock. 12 ed. Porto Alegre: Artmed, 2010.

MENEZES, E. T. N.; SILVA, G. P.; SILVA, G. F.; RUSSO, S. L. Sistema de armazenamento de água da chuva (cisternas) um estudo com enfoque em documentos de patentes. Revista Geintec, São Cristóvão/SE, v. 5, n. 2, p.21132120, 2015.

MENEZES, G. F. F.; SANTOS, D. B.; BATISTA, R. O.; AZEVEDO, D. O.; SANTANA, G. S.; SILVA, A. S.; DUARTE, A. J. A. P. Indicadores de qualidade, manejo e uso da água pluvial armazenada em cisternas do semiárido baiano. Revista Agrarian, Dourados, V. 6, n. 22, p.460-472, 2013.

MESQUITA, K. F. C.; SANTOS, M. L. S.; PEREIRA, J. A. R.; FIGUEIREDO, B. L. Avaliação da qualidade microbiológica da água consumida pela população da região amazônica um estudo de casos na ilha de Mosqueiro PA. Scientia Amazonia, v. 3, n.3, 27-31, 2014.

MINISTÉRIO DA SAÚDE. Portaria no 2.914, de 12 dedezembro de 2011. Dispõe sobre os procedimentos de controle e de vigilância da qualidade da água para consumo humano e seu padrão de potabilidade. Disponível em:<"http://bvsms.saude.gov.br/bvs/saudelegis/gm/2011/prt2914_12_12_2011.html \%20> Acesso em: 28 out. de 2013.

MINISTERIO DA SAÚDE. Portaria no 518, de 25 de março de 2004. Estabelece os procedimentos e responsabilidades relativos ao controle e vigilância da qualidade da água para consumo humano e seu padrão de potabilidade, e dá outras providências. Disponível em:<http://dtr2001.saude.gov.br/sas/PORTARIAS/Port2004/GM/GM518.htm> Acesso em: 30 ago. 2014.

OLIVEIRA, A. S.; SANTOS, D. C.; OLIVEIRA, E. N. A.; BRITO, J. G.; SILVA, W. L. Qualidade da água para consumo humano distribuída pelo sistema de abastecimento público em Guarabira-PB. Revista Verde de Agroecologia e Desenvolvimento Sustentável. Mossoró - RN, v. 7, n. 2, p. 199- 205, abr-jun, 2012.

OLIVEIRA, D. V.; SILVA, T. C.; ZAZIN, J. G. NACHTIGALL, G.; MEDEIROS, A. W.; FRAZZON, A. P. G.; VAN DER SAND, S. T. Qualidade da água e identificação de bactérias gram- negativas isoladas do Arroio Dilúvio, Porto Alegre, Rio Grande do Sul, Brasil. Evidência, Joaçaba, v. 12, n. 1, p. 51-62, Jan - Jun. 2012.

PEREIRA, C. A. R.; MELO, J. V.; MONTEIRO, C. F.; FERNANDES, A. L. T.; OKURA, M. H. O estudo da qualidade microbiológica da água de consumo humano na comunidade santa fé. Revista Saúde e Pesquisa, v. 4, n. 3, p. 393-400, set-dez. 2011. 
REIS, A. P. B.; PEIXOTO, J. C.; NUNES, J. C.; OLIVEIRA, L. S.; SEGATO, N. R.; PINTO, O. G.; SILVA, P. L.; ARAÚJO, R. C.; ABREU, T. A. A. Análise Microbiológica da Água Armazenada em Reservatório na Cidade de Campo Limpo de Goiás, GO. Revista Anápolis Digital. Anápolis- GO, v. 2, n.1, 2010.

SANTANA, F. B. F.; MARTINS, D. S. S,; OLIVEIRA, J. S.; NOBREGA, A. L. Análise microbiológica e bromatológica da água em bebedouros de escolas públicas em Belém do Brejo do Cruz-PB. Revista Verde de Agroecologia e Desenvolvimento Sustentável. Pombal, v. 10, n. 2, p. 145-149, abr-jun, 2015.

SANTOS, J. O.; SANTOS, R. M. S.; GOMES, M. A. D.; MIRANDA, R. C.; NÓBREGA, I. G. M. A qualidade da água para o consumo humano: Uma discussão necessária. Revista Brasileira de Gestão Ambiental, Pombal-PB, v. 7, n. 2, p. 1926, abr-jun, 2013.

SANTOS, L. P.; LABADESSA, A. P. S. Água: captação, tratamento e distribuição no município de Jaru/RO. Revista Fiar, Ariquemes, v.1, n.1, p.66-94, 2012.

SILVA NETO, M. D.; SANTOS, D. B.; MEDEIROS, S. S.; AZEVEDO, C. A. V.; LINS JÚNIOR, G. G.; ALMEIDA, W. C. Percepção, manejo e uso da água das cisternas em comunidade do semiárido baiano. Revista Educação Agrícola Superior, v.28, n.1, p.56-62, nov. 2013.

SILVA, C. V.; HELLER, L.; CARNEIRO, M. Cisternas para armazenamento de água de chuva e efeito na diarreia infantil: um estudo na área rural do semiárido de Minas Gerais. Engenharia Saniária Ambiental, Rio de Janeiro, v. 17, n. 4, out-dez, 2012.

SILVA, N.; SILVEIRA, N. F. A.; TANIWAKI, M. H.; SANTOS, R. F. S.; GOMES, R. A. R. Manual de métodos de análise microbiológica de alimentos. São Paulo: Livraria Varela, 1997.

SILVA, N. M. D. Qualidade microbiológica das águas de chuva em cisternas da área rural do município de Inhambupe, no semiárido baiano e seus fatores intervenientes. 2013. 130 f. Dissertação (Mestrado em Meio Ambiente, Águas e Saneamento), Universidade Federal da Bahia, Salvador.

SOUZA, J. R.; MORAES, M. E. B.; SONODA, S. L.; SANTOS, H. C. R. G. Importância da Qualidade da água e seus Múltiplos Usos. Caso Rio Almada, Sul da Bahia, Brasil. REDE - Revista Eletrônica do Prodema, Fortaleza, v. 08, n.1, p. 2645, abr. 2014. 